\title{
Using Qualitative Methods to Validate and Contextualize Quantitative Findings: A Case Study of Research on Sexual Behavior and Gender-Based Violence Among Young Swazi Women
}

\author{
Allison Ruark, ${ }^{a *}$ Rebecca Fielding-Miller ${ }^{b *}$
}

\begin{abstract}
Nesting qualitative data collection methods within quantitative studies improves results by assessing validity and providing depth and context. Using data from 3 sources from Swaziland, we triangulate qualitative and quantitative findings to highlight how different methodologies produce discrepant data regarding risky sexual behaviors among young women. We found that women reported similar numbers of lifetime sex partners in all sources, but the proportion reporting multiple and concurrent partnerships was several times higher in qualitative interviews. In addition, qualitative data can provide deeper understanding of how participants, such as those experiencing gender-based violence, understood the experiences behind the quantitative statistics.
\end{abstract}

Dr. Allison Ruark and Dr. Rebecca Fielding-Miller contributed equally to the writing of this article.

\section{INTRODUCTION}

M ost modern public health researchers in the behavioral and social sciences situate their research within a post-positivist framework, either explicitly or implicitly. ${ }^{1,2}$ Researchers working within a post-positivist framework assume that while objective "truths" of human behavior and experience exist, measuring and defining these realities is at best an approximate science. A physician or clinical researcher can measure blood pressure or CD4 count using precisely calibrated instruments and feel confident in the accuracy of the measurements, but quantifying aspects of human health and well-being is not so simple.

Social scientists and public health practitioners face multiple challenges in determining how best to measure social phenomena and various behaviors relevant to public health and how to define precisely what to measure. Efforts to conceptualize and assess important constructs such as self-efficacy, stigma, social norms, sexual identity, violence, and sexual behavior have generated a great deal of research and

\footnotetext{
a Brown University, Department of Medicine, Providence, RI, USA.

b University of California, San Diego, Division of Global Public Health, San Diego, CA, USA.

*Co-first authors.

Correspondence to Allison Ruark (AHRuark@gmail.com).
}

debate. ${ }^{3-7}$ From a post-positivist point of view, these phenomena are subjective by their very nature, making them impossible to precisely define and measure, especially in a way that is meaningful across all contexts.

In this commentary, we consider the challenges of collecting and interpreting data on sexual behavior and gender-based violence (GBV). We present a case study that illustrates challenges and potential solutions to maximize data validity and describe these behaviors and experiences as closely as possible. The comparisons and concepts come from our experience conducting 2 separate research studies in Swaziland in 2013-2014, both of which characterized sexual behavior among Swazi women in their 20s and 30s. We did not set out to collect comparable data, but we noticed that our research studies ( 1 qualitative and l quantitative using audio computer-assisted self-interviewing [ACASI]) produced very different findings about sexual behavior in research populations that seemed to be quite similar. Our data also differed markedly from the latest Swaziland Demographic and Health Survey (DHS). ${ }^{8}$ These observations led to further consideration of how different data collection methodologies and various sources of bias may influence the story that participants tell in a research interview, and how closely our research findings reflect the "true" nature of behaviors in our study populations. We believe that frank 


Measuring and
defining human
behavior and
experience is
at best an
approximate
science.

Frank
consideration of
the strengths and
weaknesses of
data collection
methodologies
is critical to
maximizing the
validity of
collected data
and the value of
research.

Using qualitative methods to collect data on sensitive topics, such as sexual history or violence, can provide critical insight and context, resulting in better interventions.

In qualitative research, the researcher is the instrument used to collect data, and therefore rapport between the researcher and participant is a critical aspect. consideration of the strengths and weaknesses of data collection methodologies is critical to maximizing the validity of collected data and the value of research.

\section{COLLECTION OF BEHAVIORAL DATA}

The collection of behavioral data in public health research rests on 2 assumptions. First, that research participants have life experiences and engage in behaviors that influence their health risks and outcomes. Second, that data collected through behavioral research can measure the "true" nature of these experiences and behaviors with enough accuracy to be useful to interventions designed to mitigate health risks. The challenge of behavioral research is to minimize the degree of error and bias, which is inevitable in all research studies, but especially in studies that use self-reported behaviors on sensitive topics.

Collecting data through self-report is often necessary for sensitive topics such as sexual history, experience or perpetration of violence, or other phenomena for which observation is problematic or impossible. Self-reported data on sensitive topics are subject to a number of wellrecognized potential biases, including social desirability bias, item response bias, reporting bias, and recall bias. ${ }^{9}$ People may report their sexual behavior inconsistently over time, ${ }^{10}$ and selfreports of sexual behavior have been found to be inconsistent with biological data ${ }^{11}$ and reports of sexual partners. ${ }^{12}$ Many types of bias derive from the data collection activity itself and are influenced by the methodology used and the skill and identity of the data collector.

There are many reasons why research participants may choose to represent their stories in research settings in a certain way. ${ }^{2}$ The interview is a "situated, social activity" in which the person being interviewed "produces, reproduces, and articulates" an identity, largely in response to rapport with and perceptions of the interviewer, ${ }^{13}$ and in response to "situational, cognitive, social, and psychological factors" ${ }^{14}$ While there is likely no research methodology that can consistently deliver data that perfectly represent reality, there are many good reasons to strive to improve the validity of the data we collect. For example, using qualitative data collection methods to understand sexual risks and experiences of sexual violence in a population can result in better interventions.

\section{Comparing the Validity of Different Methods of Collecting Data on Sexual Behavior and Gender-Based Violence}

Various studies provide evidence that study interviewers can influence participants' reports of sexual behavior ${ }^{15,16}$ or experiences of violence. ${ }^{17,18}$ In South Africa, respondents reported more conservative sexual behavior (fewer lifetime sexual partners and more condom use) to older interviewers, and men were especially likely to report fewer lifetime sexual partners to male interviewers. ${ }^{19}$ In Uganda, women were more likely to report sexual activity and willingness to use condoms to male interviewers compared with female interviewers. ${ }^{20}$ In Malawi, adolescent girls were more likely to report having had sex when asked by a nurse before testing for sexually transmitted infections, compared with face-to-face interviews or ACASI. ${ }^{10}$ In qualitative research, the researcher is the instrument used to collect data, ${ }^{21}$ and rapport between the researcher and participant is a critical aspect of data collection.

ACASI has frequently been employed to increase confidentiality and data validity in research on sexual behavior. ACASI has generally been found to yield higher reports of some sensitive sexual behaviors, but not others, compared with face-toface interviews, ${ }^{15,16,22,23}$ differing in some cases by respondent gender. ${ }^{24}$ Two 2010 reviews yielded somewhat different conclusions. Langhaug and colleagues concluded that there was "strong evidence" that computer-assisted interviewing increased reports of sensitive sexual behaviors in developing countries. ${ }^{25}$ Phillips and colleagues conducted a meta-analysis of data from low- and middle-income countries (LMICs). They concluded that compared with face-to-face interviews, other methods did not consistently yield higher reports of ever having sex, non-condom use, or number of sexual partners, but did produce higher reports of forced sex. ${ }^{26}$

We identified few studies that compared the validity of various methodologies for collecting self-reported data on GBV experiences. Interviewer training and skill is likely an important factor, and without specific training on the nature of GBV and sexual assault, even highly trained research assistants may struggle with how to categorize a particular event. ${ }^{27}$ Evaluations from the United States and Canada suggest that ACASI may capture more reports of intimate partner violence than face-to-face interviews, ${ }^{28}$ and that many women prefer disclosing these experiences to a computer rather than to another person. ${ }^{29}$ 
However, very little evidence exists on the relative validity of using ACASI to measure self-reports of violence in LMICs. In low-income communities in Bangalore, India, young married women reported significantly fewer experiences of domestic violence via ACASI than they did in face-to-face interviews. ${ }^{30}$ In these contexts, face-to-face interviews may have had higher disclosure because of their perceived cathartic value, or because of the potential of being connected to services in otherwise low-resource settings. ${ }^{30}$

Qualitative methods can increase opportunities for building trust between an interviewer and a participant and contain the flexibility to enable the participant to co-construct the interview and introduce new topics of inquiry. ${ }^{21}$ These attributes of qualitative research may produce data that are richer, more nuanced, and more valid than data collected through quantitative means. Studies of individual sexual behavior and sexual violence typically use in-depth interviews (IDIs) rather than focus group discussions (FGDs). The privacy and confidentiality of IDIs encourages participants to share their personal opinions on sensitive topics, whereas FGDs are more likely to capture data on community norms, or what FGD participants believe is socially acceptable to say in front of others. ${ }^{21,31,32}$

Survivors of violence may construct their experiences in a variety of ways depending on their cultural context, current life circumstances, and the interview scenario itself, and therefore GBV studies may particularly benefit from a qualitative approach that allows space for nuance and flexibility. ${ }^{33}$ Survivors may be reluctant to discuss experiences of violence out of shame, particularly with survey interviewers with whom they have little rapport. ${ }^{17,18}$ Survivors may not recall their experiences, or they may reconstruct what occurred in a way that distances them from stigmatized identities (such as that of a rape or sexual assault victim). ${ }^{18}$ A qualitative exploration in South Africa found that women who described non-consensual, coerced, or violent sexual experiences with intimate partners would frequently describe these experiences as disappointing, emotionally hurtful, or traumatic, but rarely categorized them as rape and often attributed them to men's "natural" sexual drives and entitlement. ${ }^{34}$

\section{The Importance of Using Mixed Methods in Research on Sexual Behavior}

It is not uncommon for large research trials to use qualitative data to contextualize quantitative findings about sexual behavior. ${ }^{35-39}$ While the The value of value of combining quantitative and qualitative combining methods in research of violence has been recognized, ${ }^{27}$ few studies using such a mixed-method approach in LMIC contexts were found in the literature. Schatz and Williams note that many researchers have called for mixed-methods research on topics related to gender, and issue a specific call for qualitative studies to validate and contextualize DHS data on gender inequality. ${ }^{40}$ Qualitative research can inform the development of structured, quantitative questionnaires, ${ }^{41}$ establish which words or phrases are locally understood to refer to acts of violence such as rape or coerced $\operatorname{sex}^{42}$ or aid researchers in navigating complex cultural minefields as they ask sensitive questions about sex and violence. ${ }^{42}$ Qualitative methods also provide context. For example, a study of GBV in the Democratic Republic of the Congo used FGDs with women who had survived violence to further explore topics addressed in a quantitative survey. The open-ended nature of the FGDs enabled women to voice concerns and priorities that had not been addressed in the quantitative survey instrument, resulting in suggestions for further research. ${ }^{43}$

Despite the frequency with which qualitative and quantitative methods are used in the same project, we identified only 1 study that used qualitative data to validate quantitative sexual behavior data. In Malawi, a qualitative study nested within a larger quantitative project found that more young women and men reported having ever had sex in IDIs compared with face-to-face surveys; $39 \%$ of young women and $17 \%$ of men gave discrepant answers in the 2 interview modalities. ${ }^{13}$ In an analysis of the IDIs, Poulin concluded that they allowed for "flexibility and reciprocal exchange" that did not exist in the surveys, thus producing trust between the interviewer and participant and resulting in more accurate reporting. ${ }^{13}$ Repeated IDIs may be especially effective in increasing rapport, and may also be useful for collecting longitudinal data on the experiences of participants over time. ${ }^{35,44-46}$

\section{CASE STUDY COMPARING DATA ON SEXUAL BEHAVIOR AND GBV FROM DIFFERENT SOURCES}

In this case study, we compare data from 3 sources: the Swaziland DHS 2006-2007; a quantitative ACASI survey of young women's sexual histories that included questions on GBV; and quantitative and

qualitative

methods in

research of

violence has been

recognized, but

few studies using

this approach in

lower- and

middle-income

countries were

found in the

literature.
GBV studies may

particularly

benefit from a

qualitative

approach that

allows space for

nuance and

flexibility. 
a qualitative interview-based study of young women's sexual partnerships that also elicited data about GBV. We provide this case study as a practical example for public health researchers and practitioners who wish to integrate qualitative methods into a quantitative study. We believe this approach can lead to better research and outcomes.

\section{Swaziland Demographic and Health Survey}

The 2006-2007 Swaziland DHS was a large, nationally representative survey carried out by the Swaziland Central Statistics Office in partnership with Macro International and the first and only DHS to be conducted in Swaziland. ${ }^{8}$ Trained Swazi data collectors administered face-to-face interviews with participants from all 4 regions of Swaziland between July 2006 and February 2007. The DHS report does not mention any effort to match interviewers to respondents by age or gender. The Woman's Questionnaire took an average of 2 hours to complete and included questions about demographic characteristics and attitudes and behaviors related to fertility and health, including a sexual partner history extending to the 3 most recent sexual partners. Nearly 5,000 women ages 15 to 49 were included in the DHS (a 94\% response rate). In this case study we present weighted data for 2,767 women ages 20 to 39 who reported ever having sex to increase comparability to other data presented. We had no role in collecting these data, but the first author (AR) extracted age-specific data from datasets made available at www.dhsprogram.com.

\section{Audio Computer-Assisted Self-Interview Survey}

Between February and June 2014, the second author (RFM) conducted a quantitative survey with 406 pregnant women ages 18 to 42 accessing antenatal care in 1 rural and 1 urban public health clinic. ${ }^{47,48}$ In this case study, we present a sub-sample of 340 women ages 20 to 39 . The survey was part of a larger mixed-methods project designed to operationalize and measure how Swazi women conceptualize transactional sex. The survey instrument included questions about lifetime and 12-month sexual partner history as well as questions adapted from the World Health Organization's violence against women instrument based on previous work conducted in South Africa. ${ }^{17,49}$ After formative and qualitative research, the survey instrument was tested for face validity with content experts and Swazi colleagues, translated into siSwati, and backtranslated into English to check translation accuracy. It was then piloted in siSwati using cognitive interviewing ${ }^{50}$ at an urban public health clinic.

Data collection was carried out using ACASI, with a young Swazi female research assistant narrating the audio track in siSwati. Participants were systematically sampled from women awaiting antenatal services at public clinics. A young female Swazi research assistant coached participants on the use of laptop computers for the initial set of demographic questions and then withdrew unless a participant requested assistance. The final survey took about 45 minutes to complete, with an approximately 54\% response rate. Per the request of the Swaziland Scientific and Ethics Committee (SEC), no incentives were offered, which may have resulted in the low response rate. Participants were offered food, drink, and childcare. Further details are available elsewhere. $^{48}$ The SEC and Emory University Institutional Review Board reviewed and approved the study protocol.

\section{Qualitative Interviews}

From June 2013 to September 2014, the first author (AR) carried out a qualitative ethnographic study of the transitions and trajectories of young Swazi adults' sexual partnerships. ${ }^{51,52}$ Data presented here are from repeated in-depth life-course interviews with 14 Swazi women between the ages of 20 and 39. Participants were recruited from a central location in Mbabane, the capital of Swaziland, and were purposively sampled to provide variation in education level, marital and relationship status, and place of residence (urban, peri-urban, and rural). Interviews were carried out in siSwati or in a mixture of English and siSwati by trained Swazi interviewers who were themselves young women in their 20s and 30s.

Each woman was interviewed 3 to 5 times, with the total average interview time per woman being over 3 hours and the average time between first and last interview being 9 months. Interviews were semi-structured and addressed family backgrounds and sexual partnership history, with emphasis given to the chronology and overlap of sexual partnerships. Each woman was encouraged to tell the story of each of her sexual 
partnerships in as much detail as she was willing to divulge. Further details about the methodology of this study are provided elsewhere. ${ }^{51,52}$ The SEC and the Institutional Review Board of the Miriam Hospital (Providence, RI, USA) approved this study.

\section{USING QUALITATIVE DATA FOR TRIANGULATION: SEXUAL BEHAVIOR}

In Figure 1, Figure 2, and Figure 3, we present sexual history data derived from the 3 sources described. Triangulating research findings from different sources provides a validity check to all data sources. We noted that women reported similar numbers of lifetime sexual partners in all surveys, with a very similar proportion of participants reporting 1 or 2 lifetime sexual partners in ACASI and DHS data, and only a small minority in all 3 surveys reporting 5 or more lifetime sexual partners. The proportion of women reporting multiple and concurrent sexual partnerships in qualitative interviews was several times that observed in the quantitative surveys, however. A substantial minority of women reported only 1 lifetime sexual partner in both ACASI and DHS data, but no participants in the qualitative interviews did so. The proportion of women who reported 2 or more sexual partners in the past 12 months among qualitative interview participants was an order of magnitude greater than the proportion reporting multiple partners among ACASI and DHS participants. Similarly, participants in the qualitative interviews were several times more likely to report having concurrent partners in the past 12 months than were participants in the ACASI survey.

We do not argue that these data are directly comparable, and we have intentionally presented them visually rather than numerically so as not to invite statistical comparison. Calculating the magnitude and significance of differences between data from these discrepant sources would be epistemologically and statistically inappropriate. These data were drawn from different populations at different points over a decade, and with somewhat different inclusion criteria. By definition, all women participating in the ACASI study had reported at least 1 sexual partner in the preceding 12 months. The ACASI and qualitative studies also used convenience samples while the DHS data attempted to create a nationally representative sample.

FIGURE 1. Number of Sexual Partners, Lifetime

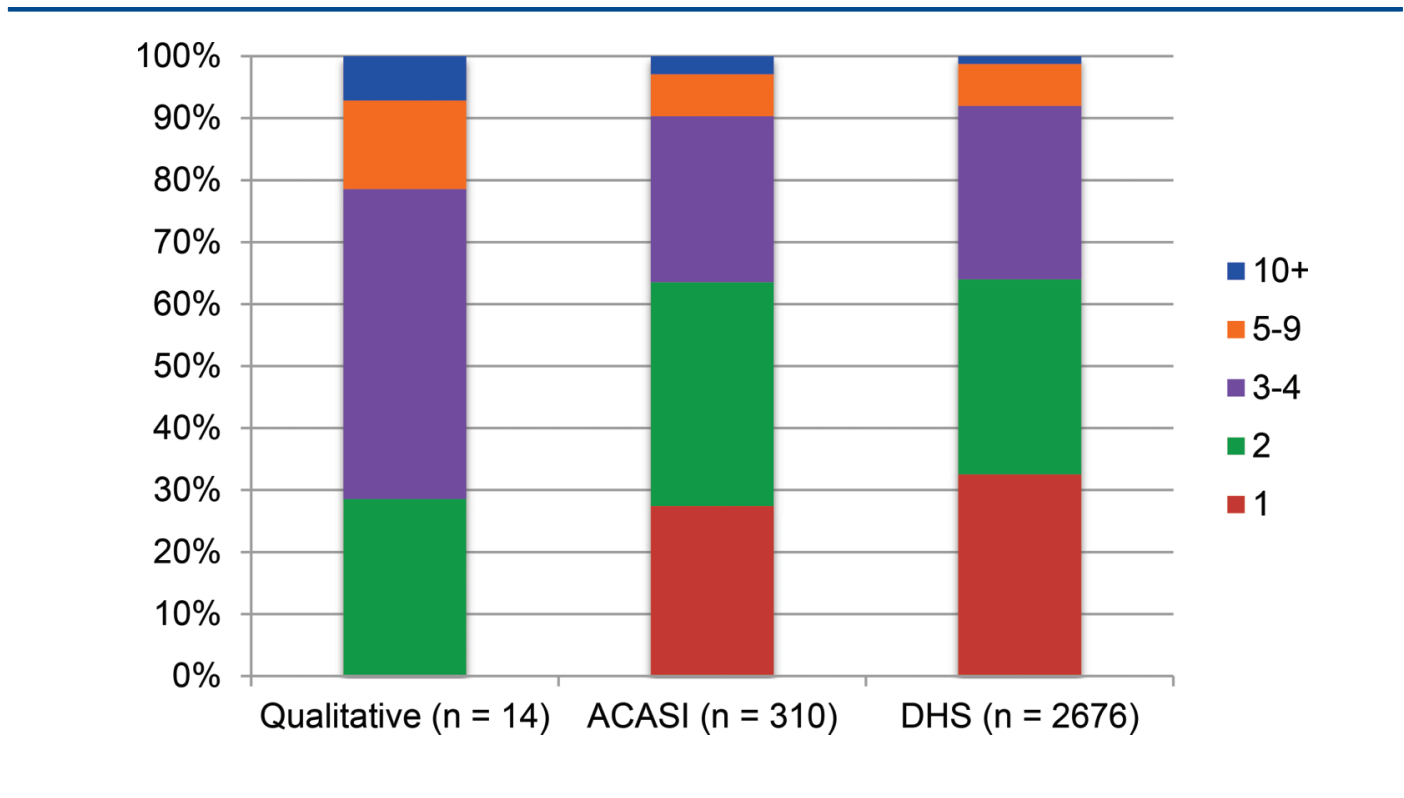

Abbreviations: ACASI, audio computer-assisted self-interviewing; DHS, Demographic and Health Survey. 
FIGURE 2. Number of Sexual Partners, Past 12 Months

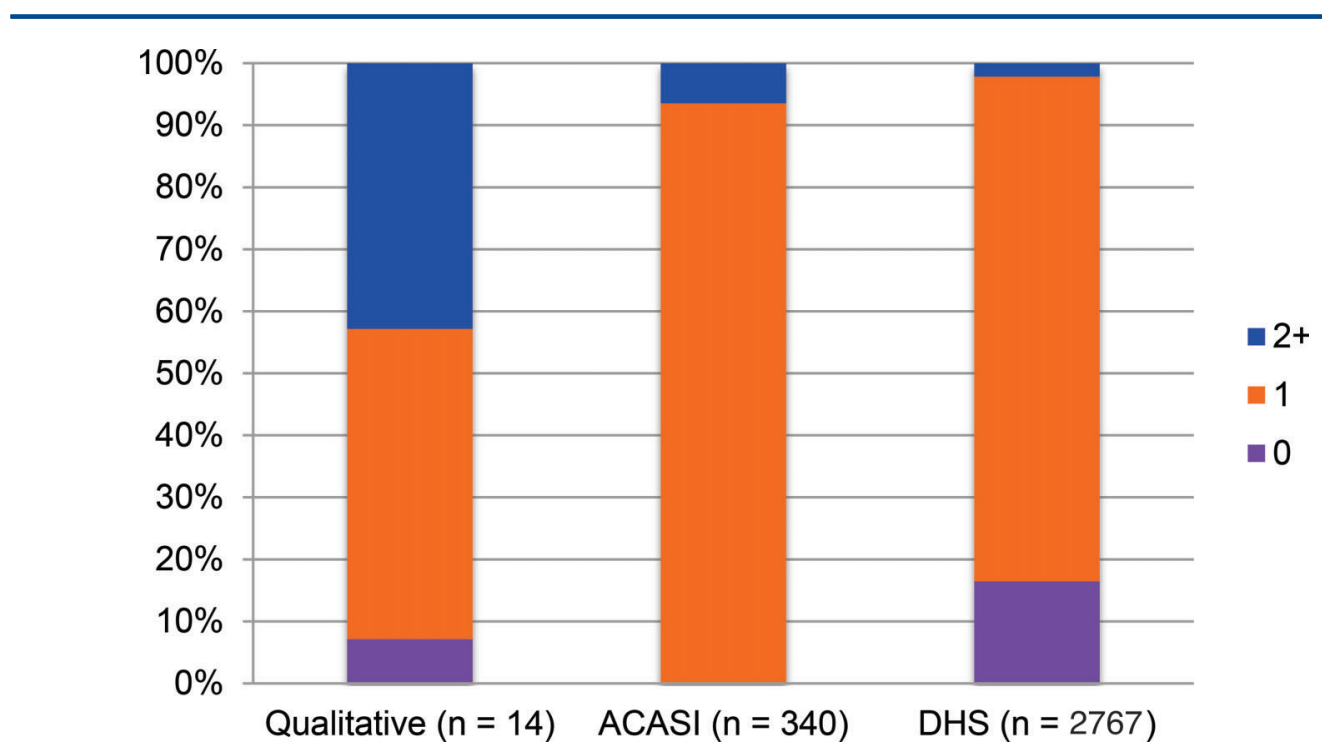

Abbreviations: ACASI, audio computer-assisted self-interviewing; DHS, Demographic and Health Survey.

FIGURE 3. Concurrent Sexual Partners, Past 12 Months

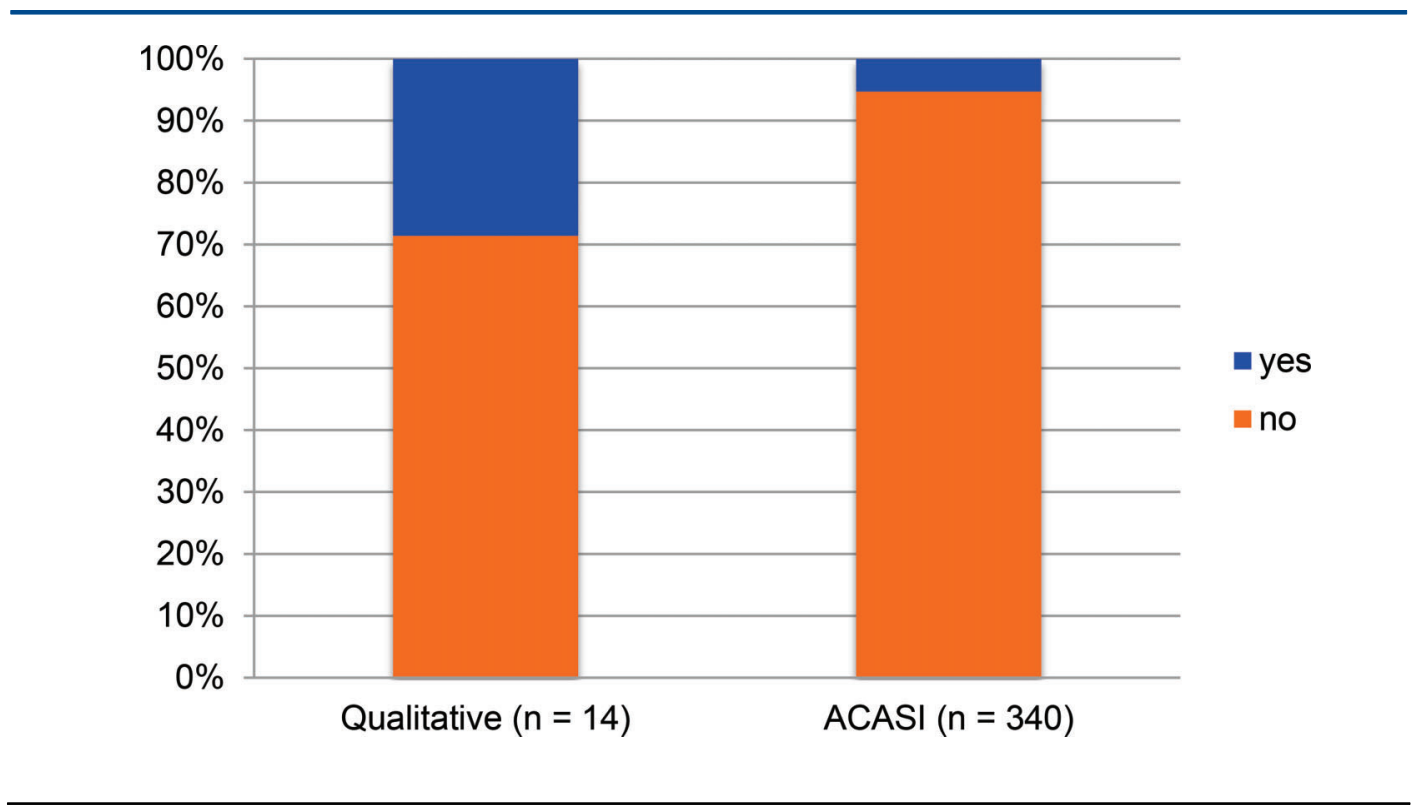

Abbreviation: ACASI, audio computer-assisted self-interviewing 
All data describe young, sexually experienced women between the ages of 20 and 39 in Swaziland. We believe the observed differences between the 3 sources are striking and strongly suggest that qualitative methods may produce higher reports of sensitive sexual behaviors than do standard quantitative surveys. We assume that Swazi women will be highly unlikely to over-report socially stigmatized behaviors (such as multiple and concurrent sexual partnerships), and therefore that data showing higher levels of socially stigmatized behaviors are more accurate.

The qualitative methods may have produced higher reports of multiple and concurrent sexual partners for 2 reasons. First, an in-depth interview enables a conversation between an interviewer and a participant that elicits a detailed story rather than isolated points of data, reducing the possibility of misunderstanding. ${ }^{21}$ The longitudinal and iterative nature of the research allowed interviewers to probe and confirm information over multiple interviews (in some cases gently challenging reports that seemed inconsistent or lacking in credibility), and to detect circumstances of risk (such as concurrent sexual partners) that may not have emerged in a once-off interview. Second, repeated interviews and the prolonged nature of the relationship between interviewer and participant created trust and rapport, which we believe increased participants' willingness to reveal sensitive information. In many cases, additional interviews increased frankness and disclosure as interviewers built rapport with participants over time, resulting in reporting of additional sexual partners.

\section{USING QUALITATIVE DATA FOR CONTEXTUALIZATION}

In the qualitative and ACASI studies, we asked women how they would describe their first sexual experience. The qualitative study focused on participants' own interpretation of their experience, whereas the ACASI study asked them to select one of multiple preexisting options: "I wanted to," "I was persuaded," "I was tricked," "I was forced", or "I was raped." A comparison of results is shown in Figure 4, with each bubble plotted on the vertical axis according to the proportion of women who reported each outcome, and with the size of each bubble representative of the absolute number of women. For the qualitative data, a brief quote is presented for each woman who reported coerced or forced first sex. While we The differences deliberately present these as a diagram to dis- between the courage direct statistical comparisons that would 3 sources strongly be inconsistent with the nature of the data, we do suggest that note that just over one-third of women in both samples described their first sexual experience as forced or coerced. This suggests that a wellimplemented ACASI survey can produce similar levels of disclosure as same-gender, face-to-face interviews with strong rapport-the suggested best practice for collecting data on violence against women. ${ }^{17,53}$

In addition to this validity check of the quantitative ACASI data, triangulating survey findings with qualitative data provides a deeper understanding of how participants understood the experiences behind the statistics, and how their understanding may have shifted over time. Just less than half of ACASI respondents reported acquiescing to sex after a partner "persuaded" or "begged" them (Figure 4). However, from the ACASI survey alone we do not know precisely how women may have experienced an encounter that they later labeled as "persuasion." Restrictive cultural norms may lead participants to select the "persuaded" option to describe a fully consensual and enthusiastic encounter if they feel it is culturally unacceptable for women to express strong sexual desire. ${ }^{54}$ Conversely, women who reported being "persuaded" by a partner could also be revising traumatic events because they feel shame admitting to experiences of sexual violence. In the qualitative data, some women recast violent or coercive events into acts of love or desire, such as this account of a woman's first sexual partner:

He used to overpower me, to be honest. We didn't have sex because we were in love ... He took advantage of me and I could see that he wanted to have sex with me and I refused. He said that I couldn't refuse now and he carried on ... I got used to him even though I was scared of him ... He saw that so he tried to bring me closer by apologizing and the relationship was okay from there.

While this participant might choose the category "I was persuaded," given limited response options in a quantitative survey about her first sexual encounter, her account suggests the difficulty of subsuming complex experiences into a single descriptor or category. We suggest there is a need for nested qualitative research to build context and "thick" description ${ }^{55}$-rich, 
FIGURE 4. Experiences of Young Swazi Women During First Sex, Qualitative Research Findings Compared With Quantitative ACASI Study Findings

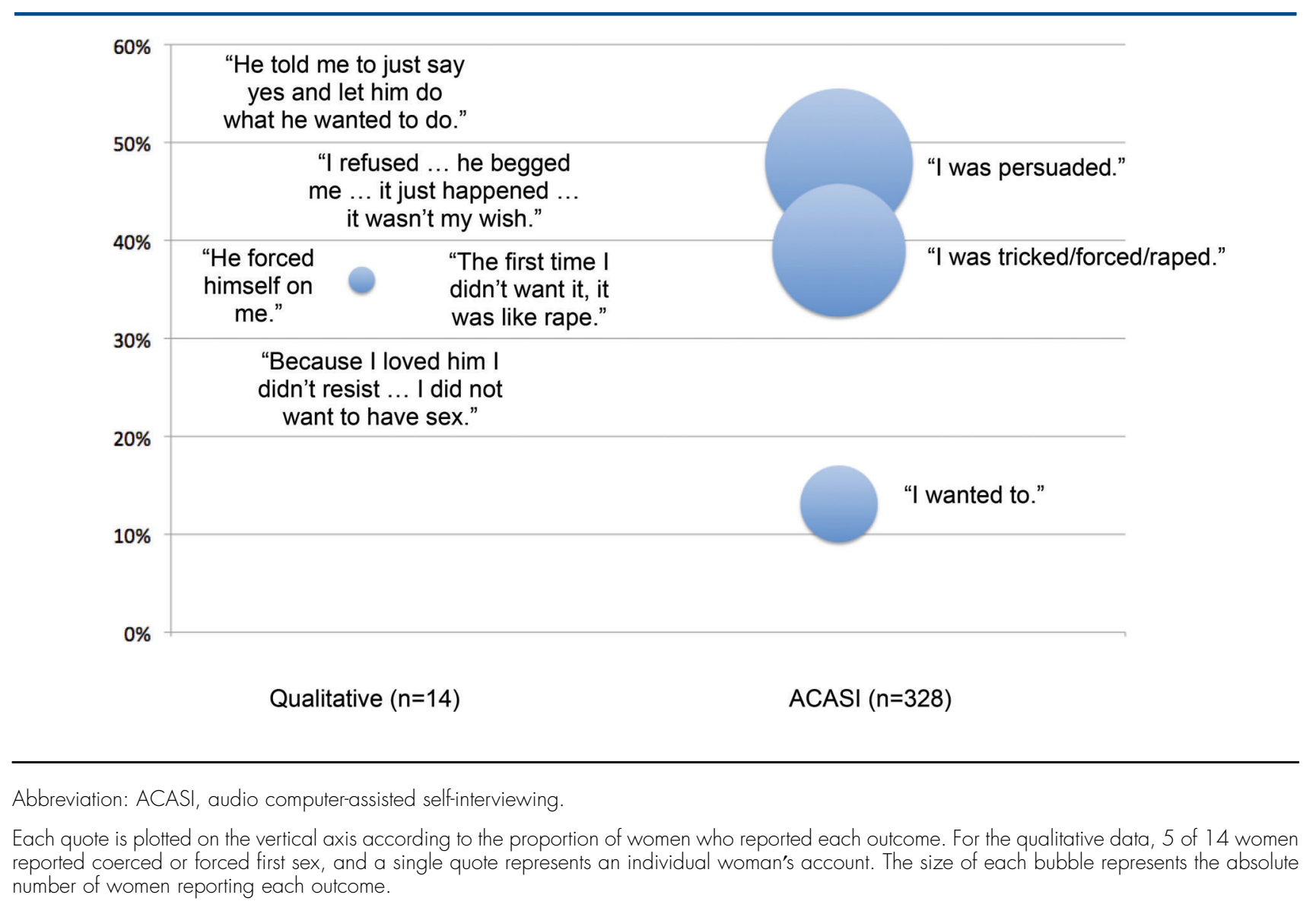

contextualized description of human behaviorinto larger observational and survey-style studies on subjects such as GBV.

\section{RECOMMENDATIONS}

Based on a comparison of multiple data sources from Swaziland, we suggest that qualitative meth-

We recommend nesting qualitative data collection within quantitative studies of sensitive topics such as sexual behavior and GBV. ods have an important role to play in research studies, including surveillance, observational, and experimental studies. Formative qualitative work before and during a quantitative survey may identify potentially unclear questions and language, improving the quality of the survey questions and final interpretation of the data. ${ }^{56}$ We also recommend, whenever possible, nesting qualitative data collection within quantitative studies of sensitive topics such as sexual behavior and GBV, in a sequential explanatory design, ${ }^{57}$ which gives priority to quantitative data but uses qualitative data to provide validation and insight into the meaning of the quantitative data (contextualization).

\section{Validation}

For topics that may benefit from better rapport between an interviewer and participant, and the opportunity to probe or revisit topics over the course of an interview, we recommend systematically sampling participants from the quantitative survey and inviting them to participate in a qualitative interview on the same topic. Although qualitative research is not traditionally used to generate statistics, data from a systematically sampled, representative subsample could provide a useful validation check on the larger quantitative project. 


\section{Contextualization}

For sensitive or ambiguous topics, in addition to rigorous qualitative formative work to build valid survey instruments, we recommend purposively sampling a subsection of participants who have participated in the quantitative data collection process, or from a similar population, to better understand the context and potential shifting meanings within a survey item. Both the methodology and underlying philosophy of qualitative research provide the flexibility to understand and report the sometimes ambiguous data that result as participants construct and reconstruct traumatic or sensitive experiences. The goal in this case is not to compare and contrast qualitative and quantitative findings, but rather to continue with qualitative investigation until the qualitative data have provided as rich, nuanced, and complete an understanding of the quantitative data as possible.

\section{Rigor}

The process of designing a qualitative study, or conducting qualitative interviews or focus groups, requires specific skill sets and explicit training. Acquiring credible, dependable, and confirmable $^{58}$ qualitative data to complement quantitative data requires careful thought and an understanding of why and how a given qualitative method (i.e., IDIs, FGDs, observation) is best suited to the question. It is also critically important to select interviewers whose age, gender, social background, and life experiences enable them to create the right kind of rapport with interview participants. Qualitative interviewers require training specific to qualitative approaches and methods to help them build rapport with a participant, feel confident deviating from interview guides when appropriate, and probe deeply to draw out participant stories.

\section{LIMITATIONS OF QUALITATIVE AND QUANTITATIVE METHODS}

Despite the importance of qualitative methods, particularly IDIs, we note that they are not appropriate for all research objectives nor are they the panacea for all data quality issues. Qualitative methods are not intended to produce generalizable statistical inferences, and they are time and energy intensive, making qualitative studies with large numbers of participants impractical. The iterative nature of data collection and analysis is also inherently dependent on the researcher-as-instrument, requiring intense and specific training to assure data quality. ${ }^{58}$ As we discuss in this commentary, quantitative methods also have substantial weaknesses; they lack the flexibility and iterative approach of qualitative research and cannot detect or correct for the distance between what a participant reports and the "truth." Mixedmethod approaches have the potential to enable qualitative and quantitative methods to work together in complementary and synergistic ways, resulting in higher-quality research.

\section{CONCLUSION}

In this commentary, we present a case study comparing 3 sources of data on sexual behavior and GBV experiences of young women in Swaziland. We highlight discrepant findings not for the purpose of statistical comparison, but as a means of discussing the importance of data collection methodology and the unique strengths of qualitative methods in providing validation and contextualization for quantitative data. The higher frequency of multiple and concurrent sexual partnerships and the rich description of GBV provided in the qualitative study suggest that qualitative methods may more closely approach the "truth" of certain behaviors and experiences. Our objective in this commentary is not to offer definitive answers regarding sexual behavior and GBV among young women in Swaziland, but to raise questions-and offer suggestions-about how research might better capture sensitive behaviors and experiences. We argue that qualitative methods are critical and underused in validating and contextualizing data collected through quantitative methods.

\footnotetext{
Acknowledgments: We thank the Swazi women who participated in our research and contributed their experiences and insights. We also thank Nonhlanhla Mazibuko, Lunga Dlamini, Mphumi Ncongwane, and Cynthia Vilakati for their assistance. Dr. Ruark acknowledges support from National Institute on Drug Abuse (NIDA) grant T32DA13911 and from the New Paradigm Fund. Dr. Fielding-Miller was supported financially and materially by a US Fulbright Grant, the USAID-funded Swaziland Health

Community Capacity Collaborative, and the Center for AIDS

Research at Emory University (P30AI050409). Support in

preparing this manuscript was provided by NIDA grants

T32DA023356 and R21DA039782.
}

Competing Interests: None declared.

\section{REFERENCES}

1. Clark AM. The qualitative-quantitative debate: moving from positivism and confrontation to post-positivism and reconciliation. J Adv Nurs. 1998;27(6):1242-1249. CrossRef. Medline

\section{Purposively sampling a subsection of informants who participated in a quantitative data collection process can help researchers better understand context and potential shifting meanings.}

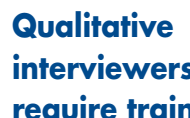
require training specific to qualitative approaches and methods to successfully draw out participant stories. 
2. Tebes JK. Community science, philosophy of science, and the practice of research. Am J Community Psychol. 2005;35(3-4): 213-230. CrossRef. Medline

3. Yang LH, Kleinman A, Link BG, Phelan JC, Lee S, Good B. Culture and stigma: adding moral experience to stigma theory. Soc Sci Med. 2007;64(7):1524-1535. CrossRef. Medline

4. Schutt RK. Conceptualization and measurement. In: Investigating the social world: the process and practice of research. 4th ed. Thousand Oaks, CA: Pine Forge Press; 2004. p. 85-126.

5. Weinstein ND. Misleading tests of health behavior theories. Ann Behar Med. 2007;33(1):1-10. CrossRef. Medline

6. Maibach E, Murphy DA. Self-efficacy in health promotion research and practice: conceptualization and measurement. Int Q Community Health Educ. 1995;10(1):37-50. CrossRef

7. Link BG, Phelan JC. Conceptualizing Stigma. Annu Rev Sociol. $2001 ; 27(1): 363-385$. CrossRef.

8. Central Statistical Office [Swaziland]; Macro International Inc. Swaziland Demographic and Health Survey 2006-07. Mbabane, Swaziland: Central Statistical Office; 2008. Co-published by Macro International Inc.

9. Fenton KA, Johnson AM, McManus S, Erens B. Measuring sexual behaviour: methodological challenges in survey research. Sex Transm Infect. 2001;77(2):84-92. CrossRef. Medline

10. Palen LA, Smith EA, Caldwell LL, Flisher AJ, Wegner L, Vergnani T. Inconsistent reports of sexual intercourse among South African high school students. J Adolesc Health. 2008; 42(3):221-227. CrossRef. Medline

11. Minnis AM, Steiner MJ, Gallo MF, Warner L, Hobbs MM, van der Straten $A$, et al. Biomarker validation of reports of recent sexual activity: results of a randomized controlled study in Zimbabwe. Am J Epidemiol. 2009; 170(7):918-924 CrossRef. Medline

12. Helleringer S, Kohler HP, Kalilani-Phiri L, Mkandawire J, Armbruster B. The reliability of sexual partnership histories: implications for the measurement of partnership concurrency during surveys. AIDS. 2011;25(4):503-511. CrossRef. Medline

13. Poulin M. Reporting on first sexual experience: the importance of interviewer-respondent interaction. Demogr Res. 2010;22(11): 237-288. CrossRef. Medline

14. Gribble JN, Miller HG, Rogers SM, Turner CF. Interview mode and measurement of sexual behaviors: Methodological issues. J Sex Res. 1999;36(1):16-24. CrossRef. Medline

15. Mensch BS, Hewett PC, Gregory R, Helleringer S. Sexual behavior and STI/HIV status among adolescents in rural Malawi: an evaluation of the effect of interview mode on reporting. Stud Fam Plann. 2008;39(4):321-334. CrossRef. Medline

16. Hewett PC. Consistency in the reporting of sexual behaviour by adolescent girls in Kenya: a comparison of interviewing methods. Sex Transm Infect. 2004;80(Suppl 2):ii43-ii48. CrossRef. Medline

17. Ellsberg $M$, Heise L. Researching violence against women: a practical guide for researchers and activists. Washington (DC): World Health Organization; 2005. Co-published by PATH. Available from: http://apps.who.int/iris/bitstream/10665/ 42966/1/9241546476_eng.pdf

18. Cook SL, Gidycz CA, Koss MP, Murphy M. Emerging issues in the measurement of rape victimization. Violence Against Women. 2011;17(2):201-218. CrossRef. Medline

19. Houle B, Angotti N, Clark SJ, Williams J, Gómez-Olivé FX Menken J, et al. Let's talk about sex, maybe: interviewers, respondents, and sexual behavior reporting in rural South Africa. Field Methods. 2016;28(2):112-132. CrossRef
20. Schopper D, Doussantousse S, Orav J. Sexual behaviors relevant to HIV transmission in a rural African population: how much can a KAP survey tell us. Soc Sci Med. 1993;37(3):401-412. CrossRef. Medline

21. Creswell JW. Qualitative inquiry and research design: choosing among five approaches. 3rd edition. Thousand Oaks (CA): SAGE; 2013.

22. van der Elst EM, Okuku HS, Nakamya P, Muhaari A, Davies A, McClelland RS, et al. Is audio computer-assisted self-interview (ACASI) useful in risk behaviour assessment of female and male sex workers, Mombasa, Kenya? PLoS One. 2009;4(5):e5340. CrossRef. Medline

23. Kelly CA, Soler-Hampejsek E, Mensch BS, Hewett PC. Social desirability bias in sexual behavior reporting: evidence from an interview mode experiment in rural Malawi. Int Perspect Sex Reprod Health. 2013;39(1):14-21. CrossRef. Medline

24. Dolezal C, Marhefka SL, Santamaria EK, Leu CS, Brackis-Cott E, Mellins CA. A comparison of audio computer-assisted selfinterviews to face-to-face interviews of sexual behavior among perinatally HIV-exposed youth. Arch Sex Behav. 2012;41(2): 401-410. CrossRef. Medline

25. Langhaug LF, Sherr L, Cowan FM. How to improve the validity of sexual behaviour reporting: systematic review of questionnaire delivery modes in developing countries. Trop Med Int Health. 2010;15(3):362-381. CrossRef. Medline

26. Phillips AE, Gomez GB, Boily MC, Garnett GP. A systematic review and meta-analysis of quantitative interviewing tools to investigate self-reported HIV and STI associated behaviours in low- and middle-income countries. Int J Epidemiol. 2010; 39(6):1541-1555. CrossRef. Medline

27. Testa M, Livingston JA, VanZile-Tamsen C. Advancing the study of violence against women using mixed methods: integrating qualitative methods into a quantitative research program. Violence Against Women. 2011;17(2):236-250. CrossRef. Medline

28. Rhodes KV, Lauderdale DS, He T, Howes DS, Levinson W. "Between me and the computer": increased detection of intimate partner violence using a computer questionnaire. Ann Emerg Med. 2002;40(5):476-484. CrossRef. Medline

29. MacMillan $\mathrm{HL}$, Wathen $\mathrm{CN}$, Jamieson $\mathrm{E}$, Boyle $\mathrm{M}$, McNutt $\mathrm{L}$, Worster A, et al. McMaster Violence Against Women Research Group. Approaches to screening for intimate partner violence in health care settings: a randomized trial. JAMA. 2006;296(5): 530-536. CrossRef. Medline

30. Rathod SD, Minnis AM, Subbiah K, Krishnan S. ACASI and face-to-face interviews yield inconsistent estimates of domestic violence among women in India: The Samata Health Study 2005-2009. J Interpers Violence. 201 1;26(12):2437-2456. CrossRef. Medline

31. Maxwell JA. Qualitative research design: an interactive approach. 3rd edition. Thousand Oaks (CA): SAGE; 2013.

32. Hennink M, Hutter I, Bailey A. Qualitative research methods. Thousand Oaks (CA): SAGE; 2011.

33. Campbell C, Mannell J. Conceptualising the agency of highly marginalised women: Intimate partner violence in extreme settings. Glob Public Health. 2016;1 1(1-2):1-16. CrossRef. Medline

34. Stern E, Buikema R, Cooper D. South African women's conceptualisations of and responses to sexual coercion in relation to hegemonic masculinities. Glob Public Health. 2016;11(1-2): 135-152. CrossRef. Medline

35. Jewkes R, Wood K, Durvury N. I woke up after I joined Stepping Stones': meanings of an HIV behavioural intervention in rural South African young people's lives. Health Educ Res. 2010; 25(6): 1074-1084. CrossRef. Medline 
36. Maman S, van Rooyen $H$, Stankard $P$, Chingono A, Muravha T, Ntogwisangu J, et al.; NIMH Project Accept (HPTN 043) study team. NIMH Project Accept (HPTN 043): results from in-depth interviews with a longitudinal cohort of community members. PLoS One. 2014;9(1):e87091. CrossRef. Medline

37. Wight $D$, Plummer $M$, Ross $D$. The need to promote behaviour change at the cultural level: one factor explaining the limited impact of the MEMA kwa Vijana adolescent sexual health intervention in rural Tanzania. A process evaluation. BMC Public Health. 2012;12(1):788. CrossRef. Medline

38. Higgins JA, Mathur S, Eckel E, Kelly L, Nakyanjo N, Sekamwa R, et al. Importance of relationship context in HIV transmission: results from a qualitative case-control study in Rakai, Uganda. Am J Public Health. 2014;104(4):612-620. CrossRef. Medline

39. Mojola SA, Williams J, Angotti N, Gómez-Olivé FX. HIV after 40 in rural South Africa: A life course approach to HIV vulnerability among middle aged and older adults. Soc Sci Med. 2015;143: 204-212. CrossRef. Medline

40. Schatz E, Williams J. Measuring gender and reproductive health in Africa using demographic and health surveys: the need for mixed-methods research. Cult Health Sex. 2012;14(7):81 1-826. CrossRef. Medline

41. Jewkes R, Vundule C, Maforah F, Jordaan E. Relationship dynamics and teenage pregnancy in South Africa. Soc Sci Med. 2001;52(5):733-744. CrossRef. Medline

42. Swiss S, Jennings PJ, Aryee GV, Brown GH, Jappah-Samukai RM, Kamara MS, et al. Violence against women during the Liberian civil conflict. JAMA. 1998;279(8):625-629. CrossRef. Medline

43. Kelly JT, Betancourt TS, Mukwege D, Lipton R, VanRooyen MJ. Experiences of female survivors of sexual violence in eastern Democratic Republic of the Congo: a mixed-methods study. Confl Health. 2011;5(1):25. CrossRef. Medline

44. Harrison A, O'Sullivan LF. In the absence of marriage: long-term concurrent partnerships, pregnancy, and HIV risk dynamics among South African young adults. AIDS Behav. 2010; 14(5):991-1000. CrossRef. Medline

45. Gysels M, Pool R, Nnalusiba B. Women who sell sex in a Ugandan trading town: life histories, survival strategies and risk. Soc Sci Med. 2002;54(2):179-192. CrossRef. Medline

46. Zalwango F, Eriksson L, Seeley J, Nakamanya S, Vandepitte J, Grosskurth H. Parenting and money making: sex work and women's choices in urban Uganda. Wagadu. 2010;8:71-92.
Available from: http://www.nswp.org/sites/nswp.org/files/ Zalwango\%20et\%20al.\%20Parenting\%20and\%20Money\% 20Making\%20Sex\%20Work\%20and\%20Women\%E2\%80\%99s\% 20Choices\%20in\%20Urban\%20Uganda.pdf

47. Fielding-Miller R, Dunkle KL, Cooper HLF, Windle M, Hadley C. Cultural consensus modeling to measure transactional sex in Swaziland: scale building and validation. Soc Sci Med. 2016;148:25-33. CrossRef. Medline

48. Fielding-Miller R, Dunkle KL, Jama-Shai N, Windle M, Hadley C, Cooper HLF. The feminine ideal and transactional sex: navigating respectability and risk in Swaziland. Soc Sci Med. 2016;158: 24-33. CrossRef. Medline

49. Dunkle KL, Jewkes RK, Nduna M, Levin J, Jama N, Khuzwayo N, et al. Perpetration of partner violence and HIV risk behaviour among young men in the rural Eastern Cape, South Africa. AIDS. 2006;20(16):2107-2114. CrossRef. Medline

50. Beatty PC, Willis GB. Research synthesis: the practice of cognitive interviewing. Public Opin Q. 2007;71(2):287-311. CrossRef

51. Ruark A, Dlamini L, Mazibuko N, Green EC, Kennedy C, Nunn A, Flanigan T, Surkan PJ. Love, lust and the emotional context of multiple and concurrent sexual partnerships among young Swazi adults. Afr J AIDS Res. 2014. 13(2):133-43. CrossRef. Medline

52. Ruark A, Kennedy CE, Mazibuko N, Dlamini L, Nunn A, Green EC, Surkan PJ. From first love to marriage and maturity: a life-course perspective on HIV risk among young Swazi adults. Cult Health Sex. 2016;18(7):812-25. CrossRef. Medline

53. Ellsberg $M$, Heise L, Peña R, Agurto $S$, Winkvist A. Researching domestic violence against women: methodological and ethical considerations. Stud Fam Plann. 2001;32(1):1-16. CrossRef. Medline

54. Schippers M. Recovering the feminine other: masculinity, femininity, and gender hegemony. Theory Soc. 2007;36(1):85-102. CrossRef

55. Geertz C. Thick description: toward an interpretive theory of culture. In: The interpretation of cultures: selected essays. New York: Basic Books; 1973. p. 3-30.

56. Nichter $M$, Nichter $M$, Thompson PJ, Shiffman $S$, Moscicki $A B$. Using qualitative research to inform survey development on nicotine dependence among adolescents. Drug Alcohol Depend. 2002;68(Suppl 1):41-56. CrossRef. Medline

57. Creswell J. Research design: qualitative, quantitative, and mixed methods approaches. 2nd edition. Thousand Oaks (CA): SAGE; 2003.

58. Lincoln YS, Guba EG. Naturalistic inquiry. 1st edition. Thousand Oaks (CA): Sage; 1985.

\section{Peer Reviewed}

Received: 2016 Feb 24; Accepted: 2016 Jun 8

Cite this article as: Ruark A, Fielding-Miller R. Using qualitative methods to validate and contextualize quantitative findings: a case study of research on sexual behavior and gender-based violence among young Swazi women. Glob Health Sci Pract. 2016;4(3):373-383. http://dx.doi. org/10.9745/GHSP-D-16-00062.

(c) Ruark et al. This is an open-access article distributed under the terms of the Creative Commons Attribution License, which permits unrestricted use, distribution, and reproduction in any medium, provided the original author and source are properly cited. To view a copy of the license, visit $\mathrm{http}: / /$ creativecommons.org/licenses/by/3.0/. When linking to this article, please use the following permanent link: http://dx.doi.org/ 10.9745/GHSP-D-16-00062. 